


\title{
Die Redtôngnumbjü̉ze
}

(x)

\author{
Röniglich Preuñijahent
}

\section{Dheruermaltungesgeridts.}

Begrümbet von $\Re$. $\mathfrak{B a r e \mathfrak { y }}$.

Bierte, gãnzlid nen bearbeitete und hiß zü Gegenwart ergänzte Fuflage,

herauşgegeben

bon

Fr. Anuze, und Dr. (S. Saum,

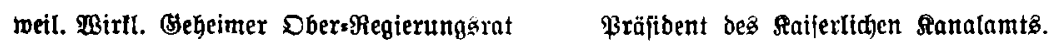

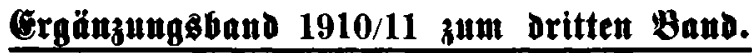

(Stenetiatien.)

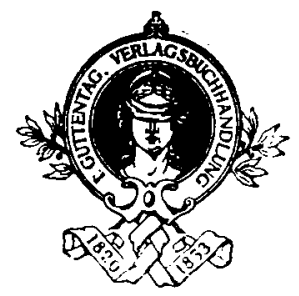

Berlin 1912.

3. Suttentag, Berlagşbudhanofung,

(s) m. b. $\$$. 


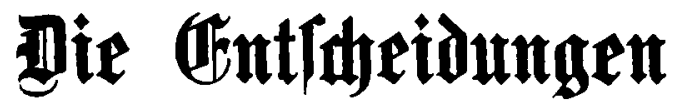

in

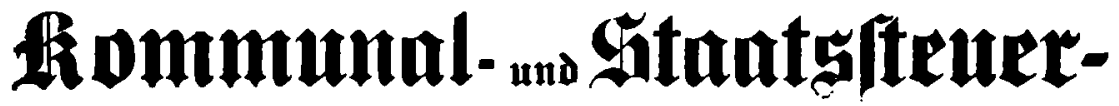 anyeleyenheiten.}

\author{
Bearbeitet \\ bon \\ Dr. (3. $9 \mathfrak{a n}$, \\ Brăfibent bes satiertid)en sanatamts.
}

Ergänzungsิband 1910/11.

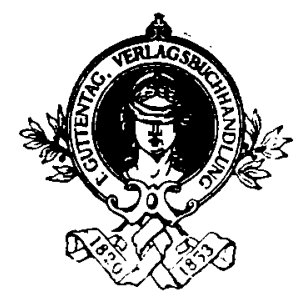

Berlin 1912.

3. Buttentag, Berlagsbudhaudrung,

(5.) ก. b. $\mathfrak{b}$. 
